\title{
Anxiety in Health Behaviors and Physical Illness
}




\section{SERIES IN ANXIETY AND RELATED DISORDERS}

Series Editor: Martin M. Antony, Professor, Department of Psychology, Ryerson University, Toronto, Ontario, Canada

ACCEPTANCE AND MINDFULNESS-BASED APPROACHES TO ANXIETY

Conceptualization and Treatment

Edited by Susan M. Orsillo and Lizabeth Roemer

CONCEPTS AND CONTROVERSIES IN OBSESSIVE-COMPULSIVE DISORDER

Edited by Jonathan S. Abramowitz and Arthur C. Houts

SOCIAL ANXIETY AND SOCIAL PHOBIA IN YOUTH

Characteristics, Assessment, and Psychological Treatment

Christopher A. Kearney

TREATING HEALTH ANXIETY AND FEAR OF DEATH

A Practitioner's Guide

Patricia Furer, John R. Walker, and Murray B. Stein

TREATING TRICHOTILLOMANIA

Cognitive-Behavioral Therapy for Hairpulling and Related Problems

Martin E. Franklin and David F. Tolin

ANXIETY IN HEALTH BEHAVIORS AND PHYSICAL ILLNESS

Edited by Michael J. Zvolensky and Jasper A. J. Smits

A Continuation Order Plan is available for this series. A continuation order will bring delivery of each new volume immediately upon publication. Volumes are billed only upon actual shipment. For further information please contact the publisher. 


\section{Anxiety in Health Behaviors and Physical Illness}

Michael J. Zvolensky

University of Vermont

Burlington, Vermont, USA

\section{Jasper A. J. Smits}

Southern Methodist University

Dallas, Texas, USA 
Michael J. Zvolensky, Ph.D. Department of Psychology University of Vermont

John Dewey Hall

2 Colchester Avenue

Burlington, VT 05405-0134

USA

Michael.Zvolensky@uvm.edu
Jasper A. J. Smits, Ph.D.

Department of Psychology

Southern Methodist University

6424 Hilltop Lane

Dallas, TX 75205

USA

jsmits@smu.edu

ISBN 978-0-387-74752-1

e-ISBN 978-0-387-74753-8

Library of Congress Control Number: 2007935078

(c) 2008 Springer Science+Business Media, LLC

All rights reserved. This work may not be translated or copied in whole or in part without the written permission of the publisher (Springer Science+Business Media, LLC, 233 Spring Street, New York, NY 10013, USA), except for brief excerpts in connection with reviews or scholarly analysis. Use in connection with any form of information storage and retrieval, electronic adaptation, computer software, or by similar or dissimilar methodology now known or hereafter developed is forbidden.

The use in this publication of trade names, trademarks, service marks, and similar terms, even if they are not identified as such, is not to be taken as an expression of opinion as to whether or not they are subject to proprietary rights.

Printed on acid-free paper.

9876554321

springer.com 


\section{Preface}

Research has been accumulating on the prevalence and nature of the cooccurrence between various forms of anxiety disorders and problematic health behaviors as well as physical illness. This research has significant implications for both those interested and affected by anxiety as well as physical health factors. Yet, it is striking that there has been little systematic integration of this health-oriented research in contemporary science and practice on anxiety and its disorders. This relative neglect is unfortunate given that the co-occurrence of anxiety and health problems is a major public health priority when measured both in human and financial terms.

The overarching aim of this book is to provide a single resource that offers current theoretical perspectives and cutting eZdge reviews of scientific research on health behaviors and physical illness in relation to anxiety and its disorders. A critical analysis of this emerging literature is needed to help move this field forward, making this proposed volume timely. The specific objectives of this edited book are to (1) provide a review of the literature on the link between anxiety and certain health behaviors and processes as well as physical illness; (2) present contemporary theories of their co-occurrence and interplay (e.g., onset, maintenance, and relapse); and (3) provide an analysis of recent research in regard to therapeutic models for targeting these problems.

The book is organized into two general sections. In the first part of the book, prototypical health behaviors - smoking, alcohol, illicit substance use, exercise, and sleep - are discussed in relation to anxiety and its disorders. In the second part of the book, the association between anxiety psychopathology and physical health conditions - chronic pain, cardiovascular disease, asthma, HIV/ AIDS - and their treatment are covered. In this same section, the potential role of puberty and the menstrual cycle in the onset and maintenance of anxiety psychopathology are discussed.

Inspection of the excellent and comprehensive works has yielded a number of broad-based conclusions relevant to informing research and practice for anxiety disorders. First, there is consistent empirical evidence that medical problems and poor health behaviors are overrepresented among persons with anxiety disorders, and vice versa. Thus, there is a pressing need to marshal information on anxiety-health processes to better serve this population. Second, as each 
contribution makes clear, there is uniform evidence that both health behaviors and physical illness can, and do, affect the nature of anxiety psychopathology. Yet, the exact nature of these associations depends on the specific disorder and health factor in question. And finally, a variety of the chapters make clear that persons suffering from anxiety psychopathology and poor health behaviors or medical illnesses may need specialized interventions to prompt clinical change. That is, traditional interventions may not be ideally suited or maximize clinical benefit for this population.

For us, the present book offers the opportunity to appreciate the importance and complexity involved with the study of anxiety disorders. For many years, health behaviors and medical illnesses have been a neglected facet of anxiety disorder research and practice. The contributions in this book help drive home the message that such neglect is unwarranted, and that by working to better understand the enigmas between health status and functioning and anxiety psychopathology, significant clinically-relevant strides can likely be achieved. We hope the present book helps move such work forward and bring a better quality of life and reduced morbidity to persons with anxiety disorders in the future.

We owe gratitude to many people who have helped us complete this project. First among these are the experts who authored the chapters. We would like to thank them for their hard work and dedication. We also appreciate the comments and suggestions of Dr. Martin Antony, the editor of the Series in Anxiety and Related Disorders, and the assistance of Anna Tobias of Spinger with the publishing of this book. Lastly, we continue to be appreciative of our respective family members, Heidi and Jack Zvolensky and Jill and Stella Smits, for their love and support.

April 2007

Michael J. Zvolensky, Ph.D. University of Vermont Jasper A. J. Smits, Ph.D. Southern Methodist University 


\section{Contents}

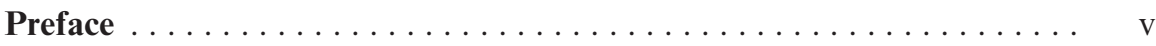

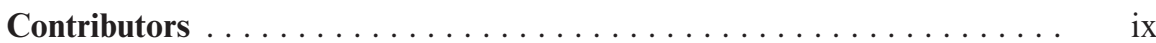

Part I: Health Behaviors and Anxiety Disorders

Tobacco Use and Panic Psychopathology: Current Status and Future

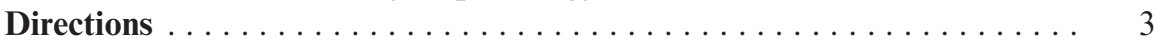

Michael J. Zvolensky, Theresa Leyro, Amit Bernstein,

Matthew T. Feldner, Andrew R. Yartz, Kimberly Babson, and

Marcel O. Bonn-Miller

Alcohol Use and Anxiety Disorders.

Brigitte C. Sabourin and Sherry H. Stewart

Illicit Drug Use Across the Anxiety Disorders: Prevalence, Underlying

Mechanisms, and Treatment .

Matthew T. Tull, David E. Baruch, Michelle S. Duplinsky,

and C. W. Lejuez

The Promise of Exercise Interventions for the Anxiety Disorders

Jasper A. J. Smits, Angela C. Berry, Mark B. Powers, Tracy L. Greer, and Michael W. Otto

Anxiety and Insomnia: Theoretical Relationship and Future

Research .............................. 105

Thomas W. Uhde and Bernadette M. Cortese

Part II: Physical Conditions and Anxiety Disorders

Anxiety Disorders and Physical Illness Comorbidity: An Overview

Tanya Sala, Brian J. Cox, and Jitender Sareen 
The Relation Between Puberty and Adolescent Anxiety: Theory

and Evidence

Ellen W. Leen-Feldner, Laura E. Reardon, Chris Hayward, and

Rose C. Smith

Anxiety, Anxiety Disorders, and the Menstrual Cycle

Sandra T. Sigmon and Janell G. Schartel

Pain and Anxiety Disorders

Gordon J.G. Asmundson, Murray P. Abrams, and Kelsey C. Collimore

Asthma in Anxiety and Its Disorders: Overview and Synthesis

Lisa S. Elwood and Bunmi O. Olatunji

Cardiovascular Disease and Anxiety

Kamila S. White

HIV and Anxiety.

Conall O'Cleirigh, Trevor A. Hart, and Carolyn A. James

Physical Illness and Treatment of Anxiety Disorders: A Review

Norman B. Schmidt, Meghan E. Keough, Lora Rose Hunter, and Ann P. Funk

Index 


\section{Contributors}

Murray P. Abrams, B.A., Anxiety and Illness Behaviours Laboratory, University of Regina

Gordon J.G. Asmundson, Ph.D. Anxiety and Illness Behaviours Laboratory, University of Regina

Kimberly Babson, B.A., Department of Psychology, University of Arkansas

David E. Baruch, Center for Addictions, Personality, and Emotion Research and the University of Maryland

Amit Bernstein, Ph.D., Veterans Affairs Palo Alto Health Care System and University of Vermont

Angela C. Berry, M.A., Department of Psychology, Southern Methodist University

Marcel Bonn-Miller, B.A., Department of Psychology, University of Vermont

Kelsey C. Collimore, B.S., Anxiety and Illness Behaviours Laboratory, University of Regina
Bernadette M. Cortese, Ph.D., Department of Psychiatry, Penn State College of Medicine and Hershey Medical Center

Brian J. Cox Ph.D., Department of Community Health Sciences and Department of Psychiatry, University of Manitoba

Michelle S. Duplinsky, Center for Addictions, Personality, and Emotion Research and the University of Maryland

Lisa S. Elwood, M.A., Department of Psychology, University of Arkansas

Matthew T. Feldner, Ph.D., Department of Psychology, University of Arkansas

Ann P. Funk, M.A., Department of Psychology, Florida State University

Tracy L. Greer, Ph.D., Department of Psychiatry, University of Texas Southwestern Medical Center at Dallas 
Trevor A. Hart, Ph.D.,

Department of Psychology,

York University

Chris Hayward, M.D., M.P.H.,

Department of Psychiatry and

Behavioral Sciences, Stanford

University

Lora Rose Hunter, B.A., Department of Psychology, Florida State

University

Carolyn A. James, M.A., Department of Psychology, York University, Toronto

Meghan E. Keough, M.S.,

Department of Psychology, Florida

State University

Ellen W. Leen-Feldner, Ph.D.,

Department of Psychology,

University of Arkansas

Carl W. Lejuez, Ph.D., Center for

Addictions, Personality, and Emotion

Research and the University of

Maryland

Teresa Leyro, B.A., Department of

Psychology, University of Vermont

Conall O'Cleirigh, Ph.D.,

Massachusetts General Hospital/

Harvard Medical School and Fenway

Community Health

Bunmi O. Olatunji, Ph.D.,

Department of Psychology,

Vanderbilt University

Michael W. Otto, Ph.D., Center for

Anxiety and Related Disorders,

Boston University
Mark B. Powers, Ph.D., Department of Psychology, University of

Amsterdam

Laura E. Reardon, M.A.,

Department of Psychology,

University of Arkansas

Brigitte C. Sabourin, B.A.,

Department of Psychology,

Dalhousie University

Tanya Sala, M.D., FRCPC,

Department of Psychiatry, University of Manitoba

Jitender Sareen B.Sc., M.D., FRCPC, Department of Community Health

Sciences and Department of

Psychiatry, University of Manitoba

Janell G. Schartel, M.A., Department of Psychology, University of Maine

Norman B. Schmidt, Ph.D.,

Department of Psychology, Florida

State University

Sandra T. Sigmon, Ph.D.

Department of Psychology,

University of Maine

Rose C. Smith, B.A.,

Department of Psychology,

University of Arkansas

Jasper A. J. Smits, Ph.D.,

Department of Psychology, Southern

Methodist University

Sherry H. Stewart, Ph.D.,

Departments of Psychiatry and

Psychology, Dalhousie University 
Matthew T. Tull, Ph.D., Center for Addictions, Personality, and Emotion Research and the University of Maryland

Thomas W. Uhde, M.D.

Department of Psychiatry, Penn State College of Medicine and Hershey Medical Center
Kamila S. White, Ph.D., University of Missouri-Saint Louis

Andrew R. Yartz, Ph.D., Department of Psychology, University of Vermont

Michael J. Zvolensky, Ph.D., Department of Psychology, University of Vermont 